a new vision and strategic direction. The outcomes and dilemmas presented by the study required further research specifically on brand. The study outcomes demonstrated a difference of view between stakeholders but provided a bold new direction for the charity and a significant change management and leadership challenge. The long term outcomes will require more time to measure. Early indicators show positive engagement with the change but stakeholder roles in the organisation and the effective management of the change are also determining factors.

Conclusions The aim is not to make fixed recommendations but to openly share both the positive and negative aspects of one organisation's experience to provide learning for others considering the same course of action. The costs, change management and reputational risk of rebranding are significant for any hospice. If the early positive indicators turn into long term benefits, a bold brand repositioning could have a significant impact in addressing long held myths and improve access to palliative care for generations to come.

\section{P-230 WHAT'S IN A NAME? TELLING OUR BRAND NEW STORY}

Emma Topping, Nigel Hartley. Mountbatten, Isle of Wight, UK

\subsection{6/bmjspcare-2018-hospiceabs.255}

Background 'The Hospice' has been engrained in people's vocabulary for over three decades. Yet today, more of our services are delivered outside of our hospice building. Whilst services had rocketed forward with new innovations, our brand was pinning us down to an old style of hospice care.

Aim

- To tell our new story

- To better explain where people's fundraising goes

- To be bolder about our fundraising ask.

Methods We were incredibly fortunate that an award-winning national brand agency donated their time and skills to create our new brand. An additional $£ 10000$ individual donation was given specifically for new signs and vehicle livery. With no further funding, our staff and volunteers were our biggest communications resource and we ensured they thoroughly understood the reasons for rebranding. We developed a strong story for them to tell, alongside answers to some anticipated questions. We held 12 open meetings, followed up with an information pack and a separate briefing was held for media and stakeholders.

A 'Letter to the Editor', embargoed press release and interviews with our CEO, additional social media and video content consolidated our key messages at no extra cost to our charity. Importantly, we retained the word 'hospice' to describe our building but in the context of our wider umbrella name.

Results

- Our retail department feeling much more 'part of the team'

- No negative coverage in local media

- Less than $£ 10,000$ (donated) spend

- Implemented within one month.

Most importantly, we had a golden opportunity to tell our new story - one that people are starting to repeat back to us. Conclusions Whilst a name change may seem peripheral to delivering hospice care, it has been fundamental to opening up services by helping people better understand how we support them and how they support us.

\section{P-231 WHAT HAPPENS WHEN A BISHOP, AN OT \& THE MD OF A DEPARTMENT STORE ARE INVOLVED IN REBRANDING A HOSPICE?}

${ }^{1,2}{ }^{2}$ Fran Hyde, ${ }^{2}$ Mark Jarman-Howe. ${ }^{1}$ University of Essex, Colchester, UK; ${ }^{2}$ St Helena Hospice, Colchester, UK

\subsection{6/bmjspcare-2018-hospiceabs.256}

Branding for hospices was recently described as a 'hot topic' (Hospice UK, 2018) in an increasingly fast-paced as well as competitive environment for hospices and at a time when organisations are placing greater emphasis on brands to differentiate (Lee \& Bourne, 2017; Chapleo, 2015; Stride \& Lee, 2007; Lee, 2013). Balancing normative (social/mission driven) and utilitarian (business driven) identities (Lee \& Bourne, 2017) hospice brands need to encapsulate a mission and represent a set of values (Stride \& Lee, 2007; Kylnader \& Sytone, 2012; Lee 2013) about a form of end of life care which they consider non-negotiable. Furthermore, a hospice brand is inherently complex needing to generate trust, foster a sense of pride amongst staff, volunteers and fundraisers, however, carrying out this work can draw accusations of inappropriate business-like behaviour by critics who perceive such use of resources unnecessary (Lee \& Bourne, 2017; Kylnader \& Sytone, 2012). Whilst several hospices have undertaken branding work (Design Week, 2017) this paper addresses the paucity of studies which consider the particular challenges of undertaking this work at hospices. Outlining an eight-month project at St Helena Hospice and disseminating key insights gained from participant observation, this paper builds on a body of work which considers the specific tensions and reactions which emerge when working with an established brand in the not-for-profit sector (Lee, 2013) and, furthermore, how such a project became an opportunity to inform and re-educate stakeholders. Accordingly, this paper has relevance for a range of stakeholders including trustees and senior leaders showing the 'doing of rebranding' focusing on how St Helena Hospice incorporated and integrated its philosophical foundations with the values and emotions of numerous, diverse stakeholders. Facilitating conversations this project broadened ambitions, implemented a new vision and re-evaluated key priorities repositioning St Helena Hospice (Lucarelli \& Hallin, 2015).

\section{P-232 HOW CAN INSTITUTIONAL THEORY HELP HOSPICES PLAN FOR THE FUTURE?}

${ }^{1}$ Emma Hodges, ${ }^{2}$ Sue Read. 'St Giles Hospice, Lichfield, UK; ${ }^{2}$ Keele University, Newcastle under Lyme, UK

10.1136/bmjspcare-2018-hospiceabs.257

There is little written about UK hospices as organisations. Given the changing nature of care as hospices increase access significantly beyond cancer, it is important to explore models of change. This research aims to highlight key concepts within institutional theory and change, that may be of interest to hospice leaders in developing and delivering their future 